\title{
Propagation of SOME TUBerous DROSERA By LEAF CUTTING
}

\author{
RoBert GIBSON • 5 Kristen Close • Cardiff Heights • NSW 2285 • Australia • robert.gibson@ \\ environment.nsw.gov.au
}

Tuberous Drosera are a large and attractive group of sundews that have generally been of limited availability in cultivation because of their slow rates of propagation. They are usually available as dormant tubers or seed. However, seed can be difficult to germinate and seedlings slow to reach maturity. A few taxa reproduce asexually by the production of daughter tubers (e.g. D. erythrorhiza Lindl., D. intricata Planch., and D. tubaestylis N.G. Marchant \& Lowrie) (Lowrie 2013)), but many remain as single plants for years. Most taxa are self-incompatible so flowering does not guarantee seed production. Tissue culture hastens seedlings to reach maturity, but not all taxa are in culture. Some novel means of asexual reproduction have been attempted, such as removing the tuber from plants in active growth (Pierson 1996), cutting dormant tubers in half (Pietropaolo \& Pietropaolo 1986), or cutting sections of stem (Lowrie 2013: Vol. 1, pp. 38-40). Leaf cuttings have been used to propagate some erect-growing taxa (e.g. Pierson 1996; Powell 1989; Pietropaolo \& Pietropaolo 1986) but this appears to have been overlooked in recent years. The technique I have used is described below.

\section{Leaf cutting plants in nature}

Vickery (1933) described plants of Drosera auriculata Backh. ex Planch. and D. peltata Thunb. in the wild with leaves that generated a stolon on the upper surface that may develop a tuber. The leaves were still attached to the plants and occurred in unusually humid conditions. She was able to generate such epiphyllous buds from plants and detached leaves in cultivation.

I have also observed leaf cuttings forming from leaves of $D$. peltata in wet locations the wild (e.g. Rowe \& Gibson 1999), but it was not until the last few years when I took a new interest in this phenomenon.

\section{Leaf cuttings in cultivation}

In winter 2015, I cut some leaves of a cultivated D. peltata plant and planted them in a wet mix of equal parts peat moss and quartz sand in a pot of Genlisea hispidula Stapf that was growing inside about $15 \mathrm{~cm}$ from a fluorescent light. The petiole was placed in a small hole, which was then backfilled to snuggly hold the detached leaf with the leaf blade at the surface of the mix. Over the next four weeks all but one leaf died. The surviving leaf remained green and formed a swollen bud on its surface from which a stolon formed that grew to the leaf edge and then grew into the mix. By early summer the leaf and stolon had died but a new tuber had formed. A new plant has emerged and grown each winter since then - but has yet to reach maturity.

In June 2016, I detached some leaves and the end of a leafy stem of a cultivated D. gigantea Lindl. plant. This time I placed these cuttings with their cut bases in a moist peat moss and quartz sand mix in a sealed rectangular plastic food container (Fig. 1). The container was placed by an east-facing window. Over the next few weeks most of the detached leaves formed a bud from which a stolon emerged that grew irregularly across the leaf surface. The swelling also produced a rosette of leaves less than $1 \mathrm{~cm}$ across. The detached stem fragment quickly rotted away save for the leaves which all produced stolons that grew into the mix. The new plants emerged in winter 1997 and formed small rosettes. 


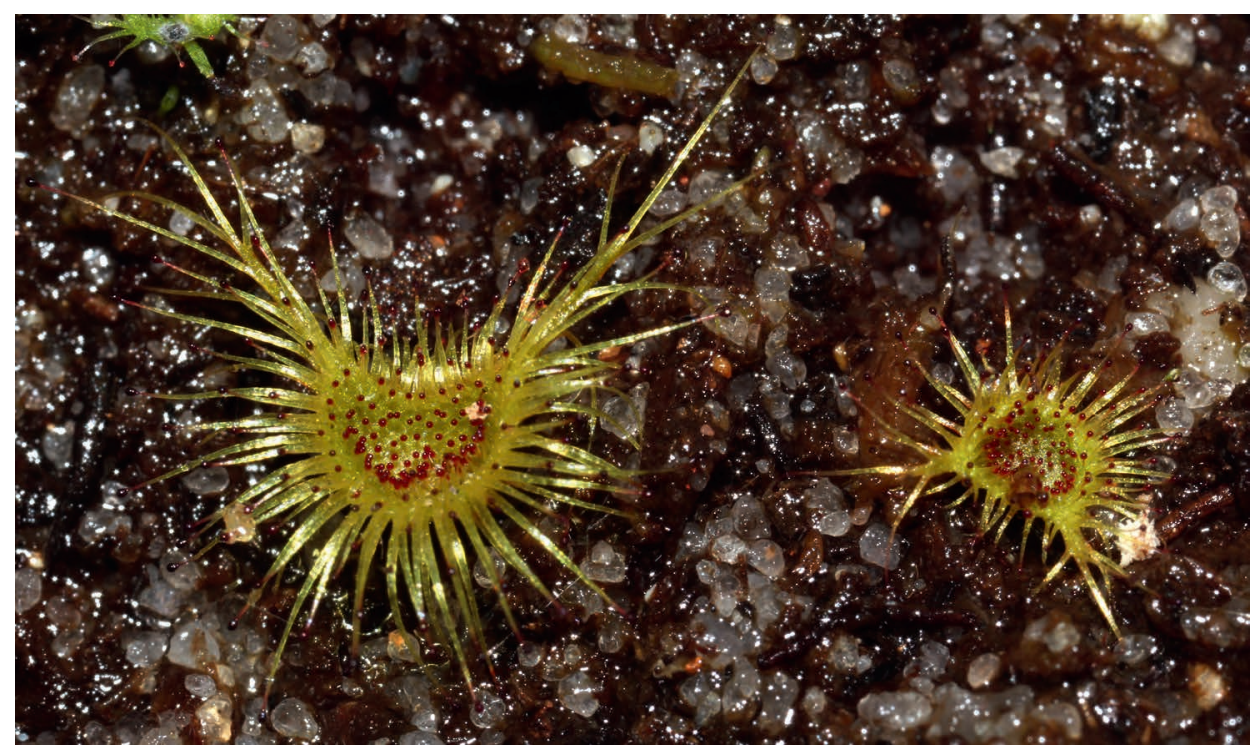

Figure 1: Six weeks after harvest these leaves of Drosera gigantea have epiphyllous buds that are developing a rosette of small leaves.

In July 2017, I detached three leaves from plants of D. gigantea, D. macrantha Endl., D. stricticaulis (Diels) O.H.Sarg., and D. sulphurea Lehm. The leaves of D. macrantha and D. stricticaulis rotted without producing any stolons; perhaps because these species are adapted to drier conditions? However, leaves from D. gigantea, once again, formed small buds within six weeks, from which stolons and small rosettes developed (Fig. 2). Sometimes the stolon did not clear the leaf blade and instead formed the tuber on the leaf surface, beside the rosette. Two of the D. sulphurea produced a stolon. One cleared the leaf blade, grew down about $1.5 \mathrm{~cm}$ long and formed a tuber about $2 \mathrm{~mm}$ diameter before the parent leaf died (Fig. 3). By early December 2017, the stolon on the other leaf had not reached the leaf margin but had a short leafy stem and developing stolon (Fig. 4).

The small sample has yielded a success rate of over $50 \%$ for $D$. gigantea and $D$. sulphurea leaf cuttings. Successful leaves form single tuber about $2 \mathrm{~mm}$ diameter within 4 or 5 months. The tuber may be left where it has formed (or buried the same depth as the tuber if it has formed on the parental leaf blade) where it will regrow the following autumn. They require a more humid version of the growing conditions of the parent plant to develop epiphyllous buds.

This technique offers a cheap and simple means of propagating some tuberous Drosera that otherwise tend to remain as single plants in a collection, and also in propagating attractive forms of some taxa - such as the all-red form of D. gigantea. While raising clones will not solve the problem of self-incompatibility it may provide a means of generating new stock to trade for different plants that may open the option of seed production in the future.

To date, it seems this technique works for erect-growing tuberous Drosera that are native to wet habitats. It appears likely to work for such taxa as D. bulbigena Morrison, D. geniculata (N.G.Marchant \& Lowrie) Lowrie (e.g. see Lowrie 2013: Vol. 1, p. 39), D. neesii Lehm., and maybe even swamp-growing plants of $D$. fimbriata DeBuhr? 


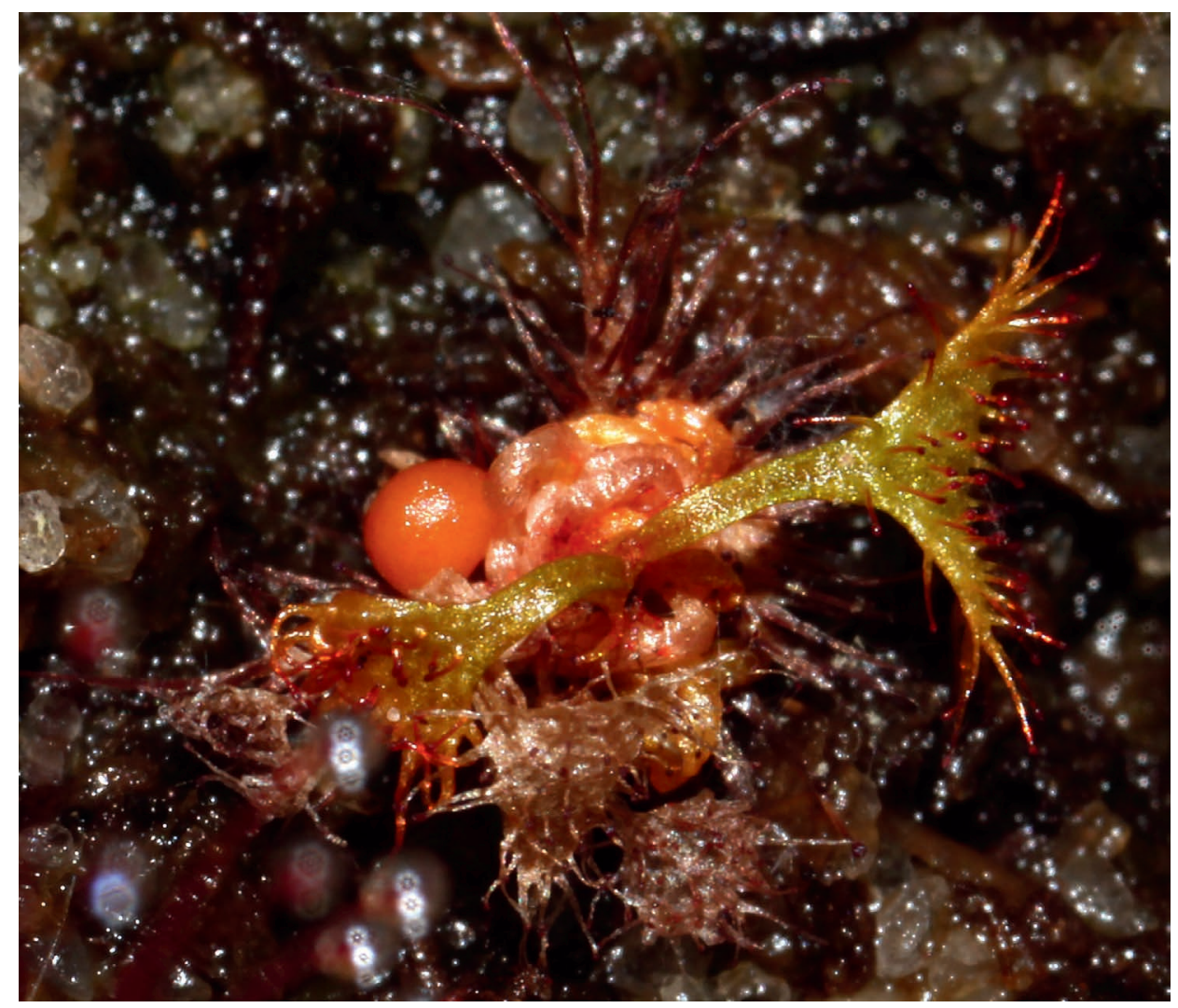

Figure 2: Drosera gigantea leaf cutting with a developing tuber. The parent leaf has rotted away.

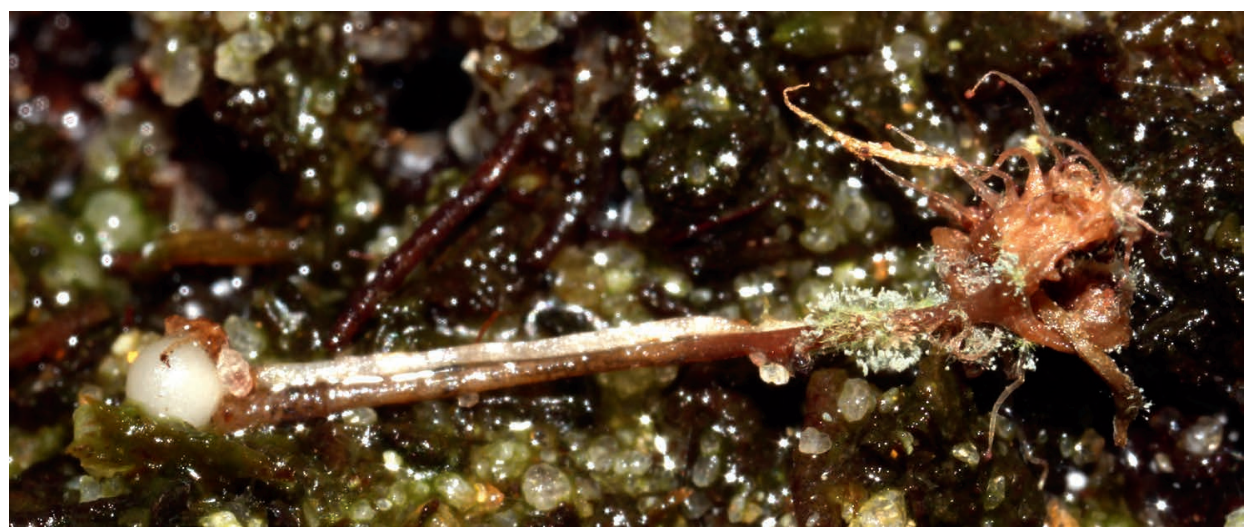

Figure 3: Drosera sulphurea leaf cutting that formed a stolon and small tuber. 


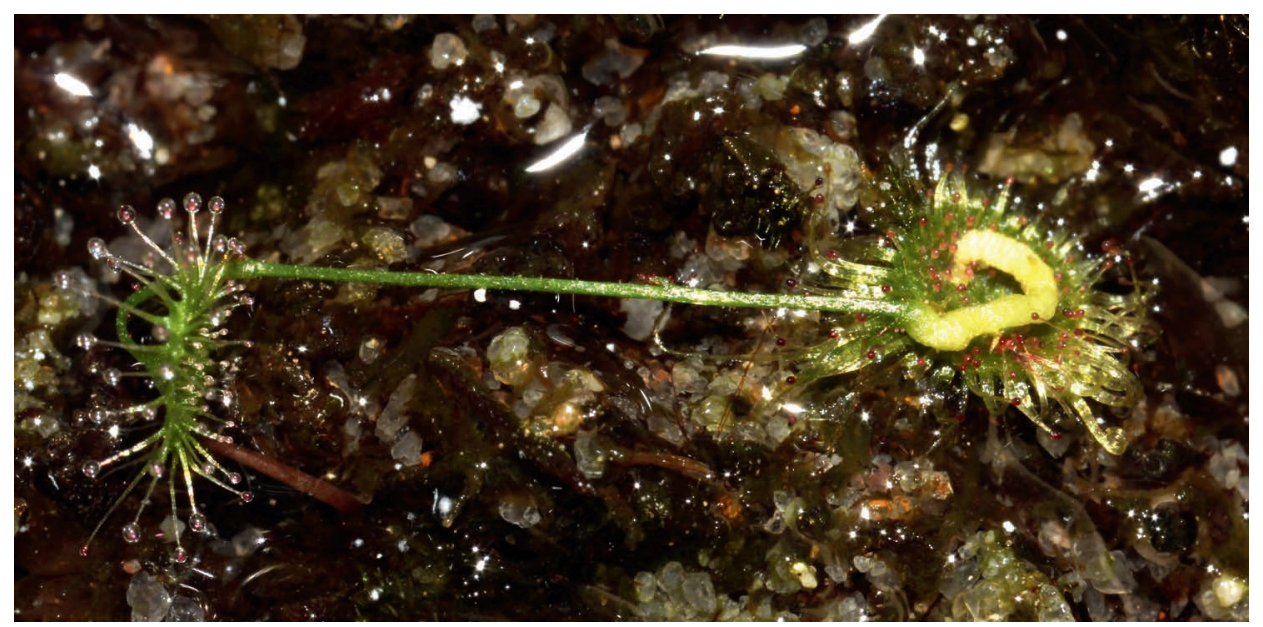

Figure 4: Epiphyllous bud of Drosera sulphurea with a leafy stem and a developing stolon.

\section{Conclusions}

Leaf cuttings are a viable way to propagate some taxa of tuberous Drosera. They have worked for a number of erect-growing taxa that tend to grow in wet conditions. This technique requires a small amount of plant material but offers a chance to propagate some very attractive plants. It is worth giving it a go.

Acknowledgements: I thank Greg Bourke, Kirk 'Füzzy’ Hirsch, Richard Jobson, and Ross Rowe for assistance with fieldwork in which observations of natural leaf cuttings of $D$. auriculata and $D$. peltata were observed in the wild.

\section{References}

Lowrie, A. 2013. Carnivorous Plants of Australia Magnum Opus. Redfern Natural History Productions, Poole.

Pierson, B. 1996. Followup on tuberous Drosera propagation. Carnivorous Plant Newsletter 25: 121-122.

Pietropaolo, J., and Pietropaolo, P.A. 1986. Carnivorous Plants of the World. Timber Press, Portland.

Powell, C.L. II. 1989. Tuberous Drosera. Carnivorous Plant Newsletter 18: 21-26.

Rowe, R., and Gibson, R. 1999. In search of Drosera peltata var. gracilis and tuberous Utricularia dichotoma in the Southern Tablelands, NSW. Journal of the Australian Carnivorous Plant Society $18: 14-17$.

Vickery, J. 1933. Vegetative reproduction in Drosera peltata and Drosera auriculata. Proceedings of the Linnean Society of New South Wales 58: 245-269. 